Wier, M.F. van, Verweij, L.M., Proper, K.I., Hulshof, C.T.J., Tulder, M.W. van, Mechelen, W. van. Economic evaluation of an occupational health care guideline for prevention of weight gain among employees. Journal of Occupational and Environmental Medicine: 2013, 55(9), 110e-1109

nivel

\begin{tabular}{|l|l|}
\hline $\begin{array}{l}\text { Postprint } \\
\text { Version }\end{array}$ & 1.0 \\
\hline Journal website & $\frac{\text { http://journals.Iww.com/joem/pages/articleviewer.aspx?year=2013\&issue=09000 }}{\text { \&article=00014\&type=abstract }}$ \\
\hline Pubmed link & $\underline{\text { http://www.ncbi.nlm.nih.gov/pubmed/23969508 }}$ \\
\hline DOI & $10.1097 /$ JOM.0b013e31829b279a \\
\hline
\end{tabular}

This is a NIVEL certified Post Print, more info at http://www.nivel.eu

\title{
Economic Evaluation of an Occupational Health Care Guideline for Prevention of Weight Gain Among Employees
}

\author{
VAN Wier, MARIEKe F. PhD; VerWeiJ, LisAnNe M. PhD; PROPER, KARIN I. PhD; \\ Hulshof, Carel T.J. PhD; VAn Tulder, Maurits W. PhD; VAn Mechelen, Willem \\ PHD
}

\begin{abstract}
Objective: To determine the cost-effectiveness and the financial return of a guideline for occupational physicians (OPs), aimed at the prevention of weight gain among employees.

Methods: The guideline consisted of a company-environment scan and up to five individual sessions with an OP. Sixteen OPs randomized to the guideline (n $=7)$ or usual care group $(n=9)$ recruited 275 and 249 employees. Costs were collected by using 3-monthly retrospective questionnaires. Quality-adjusted lifeyears gained were determined with 6-monthly administered EuroQol-5D. Waist circumference and body weight were measured at baseline and 18 months.
\end{abstract}

Results: Unfavorable differences were found on waist circumference $(+1.6 \mathrm{~cm}$; 95\% confidence interval [CI], 0.27 to 2.90$)$ and weight ( $+1.1 \mathrm{~kg} ; 95 \% \mathrm{CI}, 0.01$ to 2.15). Probabilities of cost-effectiveness were consistently less than $55 \%$. Net employer loss was €-158 (95\% CI, -2865 to 2672).

Conclusions: The occupational health care guideline was not cost-effective and no financial return was shown.

The global increase in overweight and obesity is widely acknowledged as a major public health problem. ${ }^{1}$ Obesity is associated with high health care costs, ${ }^{2}$ as well as increased sick leave, disability, and productivity loss in the working population. ${ }^{3}$ Occupational physicians (OPs) could play an important role in the prevention of overweight. In the Netherlands, about $44 \%$ of the population is employed and almost all of these employees have access to an OP. Nevertheless, OPs often lack knowledge and methods to adequately address lifestyle change among the workforce. For that reason, an evidence-based occupational health care guideline for the prevention of weight gain among employees was developed and evaluated. ${ }^{4-6}$ When making decisions about the implementation of occupational health care interventions, the trade-off between costs and benefits should be considered. In the 
Wier, M.F. van, Verweij, L.M., Proper, K.I., Hulshof, C.T.J., Tulder, M.W. van, Mechelen, W. van. Economic evaluation of an occupational health care guideline for prevention of weight gain among employees. Journal of Occupational and Environmental Medicine: 2013, 55(9), 1101-1109

Netherlands, employers are the major payers of occupational health care and prevention programs. They may be most interested in knowing their financial return from investments in preventive measures. ${ }^{7}$ Nevertheless, because costs and benefits may also fall on other payers within society, economic evaluations from a societal perspective are also of importance. ${ }^{8}$

The aims of this study were, therefore, to compare the occupational health care guideline with usual care in terms of cost-effectiveness and cost-utility from the societal perspective as well as to perform a financial return analysis from the Dutch employer perspective.

\section{METHODS}

\section{Design of the Study}

An economic evaluation was conducted alongside the Balance@Work study, a cluster randomized controlled trial (RCT) carried out in the Netherlands from 2009 to 2011. The time horizon of the study was 18 months. Full details of the study design and the draft guideline have been published previously. ${ }^{4}$ The study design and informed consent procedure were approved by the medical ethics committee of the VU University Medical Center, and all participants provided written informed consent. The trial is registered as ISRCTN/73545254 and NTR/1190.

\section{Study Population}

Occupational physicians providing services to 1 or more companies with more than 100 workers were recruited through a direct mailing by the Netherlands Society of Occupational Medicine (in Dutch, “NVAB”). Twenty-eight OPs were randomized and requested to recruit at least 30 employees with unhealthy physical activity and/or dietary behavior or who were overweight. ${ }^{4}$ Employees were excluded when pregnant, in cases where a disease or condition that made physical activity impossible was present, when absent from work for 21 days or longer, or if they were unable to complete a questionnaire in Dutch. Between randomization and baseline measurements, ${ }^{12}$ OPs withdrew because of lack of time $(n=3)$ or because the company they were servicing withdrew $(n=9)$. This left seven OPs in the guideline and nine in the usual care group.

\section{Interventions}

The intervention consisted of an environmental scan at baseline and after 6 months, assessing whether or not the company facilities were conducive to prevention of weight gain. ${ }^{4}$ Occupational physicians discussed the results of the scan with the employer and workers' representative council. The guideline further consisted of five 20- to 30-minute individual counseling sessions with an OP, of which two sessions could be done by phone, to be completed within 6 months. Occupational physicians received training in behavioral-change counseling techniques, that is, motivational interviewing, aimed at physical activity and diet. In addition, OPs and employees were provided with informational tools. Occupational physicians received written materials they could use during the counseling sessions. Employees received a waistcircumference measure tape, a pedometer, and information leaflets on physical activity and nutrition from the Netherlands Heart Foundations and the Netherlands Nutrition Centre and a diary to monitor daily physical activity and diet. The control group received care as usual, consisting of health care advice by the OP, directed at the findings of the health risk assessment performed at baseline. Usual 
Wier, M.F. van, Verweij, L.M., Proper, K.I., Hulshof, C.T.J., Tulder, M.W. van, Mechelen, W. van. Economic evaluation of an occupational health care guideline for prevention of weight gain among employees. Journal of Occupational and Environmental Medicine: 2013, 55(9), 110 -1109

care is the most relevant comparison because this would be replaced by the guideline-based care.

\section{STUDY MEASURES}

\section{Health-Related Outcomes}

The primary outcome of the study was waist circumference, with body weight as a secondary outcome. Baseline body measurements were done during a health risk appraisal by the OPs or their assistants, who were trained and followed a standard protocol. ${ }^{4}$ Waist circumference was measured midway the lower rib margin and the iliac crest to the nearest $0.1 \mathrm{~cm}$, using a tape measure (Seca 201; Seca, Hamburg, Germany). Weight was measured to the nearest $0.5 \mathrm{~kg}$ with a scale available at the office of the OP. The EuroQol-5D was used to assess quality of life. ${ }^{9}$ Health utilities were estimated with the Dutch tariff.10 Quality-adjusted life-years (QALYs) were calculated by multiplying the utilities with the amount of time a participant spent in a particular health state. Transitions between health states were linearly interpolated. Measurements took place at baseline and after 6, 12, and 18 months.

\section{Health Care Costs, Participant Costs, and Productivity-Loss Costs}

Information on health care utilization, participant costs, and productivity loss was obtained through six retrospective 3-month questionnaires. Health care utilization consisted of primary health care (general practitioner, allied health care) and secondary health care (medical specialist, hospitalization) and was valued with Dutch standard costs. ${ }^{11}$ When these were not available, prices reported by professional associations were used. Participants' costs concerned self-reported costs associated with improving physical activity, such as sports club memberships and sports equipment. Costs of productivity loss included absenteeism and presenteeism, that is, lower performance while at work.

Absenteeism was assessed by using an item of the Productivity and Disease Questionnaire, asking workers to report their total number of sick leave days during the past 3 months. ${ }^{12}$ These were multiplied with the number of hours that an employee reported to work per day. Labor costs associated with 1-hour sick leave were calculated per worker by dividing their yearly labor costs (self-reported net salary, with added taxes and benefits) by their total number of workable hours per year. ${ }^{11}$ We used the friction cost approach with a friction period of 23 weeks (ie, the period needed to replace a sick worker) and an elasticity of $0.8 .{ }^{11,13,14}$ An elasticity of 0.8 implies that full-time absenteeism corresponds to an $80 \%$ loss in productivity. ${ }^{13}$

Presenteeism was assessed by using an item of the World Health Organization Health and Work Performance Questionnaire, asking workers to rate their overall work performance during the previous 4 weeks on a 11-point scale, ranging from "worst performance" (0) to "best performance" (10). ${ }^{15}$ Assuming linearity, the average work performance during the 3-month follow-up period $\left(\mathrm{WP}_{\text {own }}\right)$ was calculated. A worker's level of presenteeism was calculated by using the following formula: Presenteeism score $=\left(10-\mathrm{WP}_{\mathrm{own}}\right) / 10$.

Presenteeism hours were calculated by multiplying a worker's presenteeism score by the number of hours worked in the previous 3 months, that is, working hours minus sick leave. Presenteeism hours were valued with the employee's hourly labor cost. 16,17 
Wier, M.F. van, Verweij, L.M., Proper, K.I., Hulshof, C.T.J., Tulder, M.W. van, Mechelen, W. van. Economic evaluation of an occupational health care guideline for prevention of weight gain among employees. Journal of Occupational and Environmental Medicine: 2013, 55(9), 110e-1109

Prices were adjusted for the year 2009, the year of the first measurement, using consumer price indices.18 No discounting was done for the costs in months 13 to 18 because this would have had little effect on the total costs. All prices used are given in the supplemental material (see Table, Supplemental Digital Content 1, which shows the price weights for resource use).

\section{Guideline Costs}

Bottom-up microcosting was used to estimate the cost of using the guideline (see Table, Supplemental Digital Content 2, which shows the detailed calculation of the interventions costs).19 An estimated 488 OPs (22\%) in the Netherlands are paid by companies to give lifestyle advice.20-22 In the Netherlands, occupational guidelines are in general updated every 5 years. Costing was based on projections of the Netherlands Society of Occupational Medicine that 6\% of the 448 OPs would start using the guideline in the first year, rising to $30 \%$ in the fifth year. Occupational physicians are expected to apply the counseling to 50 employees from three companies per year. Thus, in total, 21,950 employees ( $0.3 \%$ of the Dutch workforce) would be counseled in 5-year time.

Guideline costs consisted of fixed and variable costs. The fixed costs covered costs of the development of the guideline and printing of materials, training of the OPs, costs for selecting and inviting the participants, and both OP costs and employer time costs for the environmental scan. Printing of materials was valued, using charges paid. Time investments were valued, using labor costs. A second calculation was done to facilitate the financial return analyses from the employer's perspective, using commercial prices charged to companies for time invested by the OP. Total fixed costs per participant were $€ 43.76$, using labor costs, and $€ 100.24$, using commercial prices.

Variable costs per participant depended on the number and duration of contacts that had been registered by the OP. Duration of the sessions, including administration, was estimated by the OPs at 30 minutes for the first session and 20 minutes for sessions 2 to 5 . Costs included labor costs for the OP and labor costs for the employee. In the financial return analyses, OP time was valued with commercial prices. Guideline costs per employee consisted of the total of fixed and variable costs.

\section{STATISTICAL ANALYSES}

\section{Multiple Imputation}

Intention-to-treat analyses were performed; missing data were imputed by using multiple imputation techniques. To build the imputation model, complete cases were compared with incomplete cases within each study group. Chi-square tests and tests were used for this comparison. The imputation model included, among others, age, sex, educational level, baseline outcome values, available midpoint (6 and 12 months) and follow-up outcome values, the number of counseling sessions attended, and available health care costs, participant costs, sick leave days, and presenteeism at each 3-month cost measurement. Imputations were done separately for the intervention and control group. Because resource-use data were skewed and showed an excess of zeros, resource use (except for the number of counseling sessions, absenteeism days, and presenteeism) was imputed on an aggregated cost level. Ten different data sets were created in Statistical Package for the Social Sciences (version 
Wier, M.F. van, Verweij, L.M., Proper, K.I., Hulshof, C.T.J., Tulder, M.W. van, Mechelen, W. van. Economic evaluation of an occupational health care guideline for prevention of weight gain among employees. Journal of Occupational and Environmental Medicine: 2013, 55(9), 110e-1109

17.0.2; Statistical Products and Service Solutions, Inc, Chicago, IL), using Fully Conditional Specification and Predictive Mean Matching procedures. ${ }^{23}$ These data sets were analyzed as specified hereafter. The estimates were pooled with methods described by Rubin. ${ }^{24}$ This method does not allow for an estimation of standard deviations, so the standard error of the mean is presented to describe variability.

\section{Effectiveness, Cost-Effectiveness, and Cost-Utility Analyses}

Regression analysis was used to compare health-related outcomes, sickness absenteeism hours, and presenteeism hours between the intervention and control groups. Follow-up outcomes were adjusted for baseline values. ${ }^{25}$ To compare costs between groups, 95\% confidence intervals (CIs) around the mean differences in costs were estimated by using approximate bootstrap confidence intervals with 2000 replications. ${ }^{26}$ Incremental Cost-Effectiveness Ratios (ICERs) and Incremental CostUtility Ratios (ICURs) were estimated by dividing the difference in total costs between the treatment groups by the difference in adjusted health-related outcomes. To graphically present uncertainty around the ratios, cost-effectiveness planes with 2000 bootstrapped cost-effectiveness pairs were plotted, ${ }^{27}$ and cost-effectiveness acceptability curves produced by using the net health benefits approach. ${ }^{28}$

\section{Financial Return Analyses}

Using the costs and benefits of the program, three outcomes were calculated: (1) net benefits (NB), (2) benefit-cost ratio, and (3) return on investment. ${ }^{29,30}$ Costs were defined as the costs of providing guideline-based care. Benefits were defined as the difference in monetized productivity loss (ie, absenteeism and presenteeism costs) between both groups during follow-up. Net benefits consisted of the guideline costs subtracted from its benefits. Benefit-cost ratio was calculated by dividing the benefits by the costs. Return on invest was the division of NB by the costs, multiplied by 100 . To quantify precision, $95 \%$ CIs around the NB were estimated by means of approximate bootstrap confidence intervals with 2000 replications. $^{26}$ Financial returns are positive if the following criteria are met: NB $>0$, benefit-cost ratio $>1$, and return on invest $>0$.

\section{Sensitivity Analyses}

Sensitivity analyses were conducted to test the robustness of the results. First, analyses were performed by using cases with complete data for both outcomes and costs, that is, complete cases (SA1). Second, costs for productivity losses were estimated by using standard mean labor costs of the Dutch population, that is, €30.02 per hour ${ }^{11}$ (SA2). Third, analyses were performed in which absenteeism costs were estimated by using the human capital approach instead of the friction cost approach (SA3). In the human capital approach, total sick leave days are neither "truncated" as in the friction cost approach nor is elasticity considered. Fourth, because overall consensus about whether or not to include presenteeism costs in economic evaluations does not exist currently, analyses were performed in which presenteeism costs were excluded (SA4). ${ }^{31}$

\section{RESULTS}

\section{Participants}

The flow of OPs and employees is shown in Fig. 1. After completion of the intervention period, three OPs were lost to follow-up, of whom one did not report on 
Wier, M.F. van, Verweij, L.M., Proper, K.I., Hulshof, C.T.J., Tulder, M.W. van, Mechelen, W. van. Economic evaluation of an occupational health care guideline for prevention of weight gain among employees. Journal of Occupational and Environmental Medicine: 2013, 55(9), 110e-1109

use of the intervention among his employees. Subsequently, the employees of these OPs were measured by the Balance@Work team. Six OPs had difficulties in performing follow-up measurements, resulting in missing data (Fig. 1).

\section{[FIGURE 1]}

The OPs recruited 524 participants. After 18 months, 70 intervention employees (26\%) and 54 control employees (22\%) were lost to follow-up. Reasons for loss to follow-up were in majority loss of motivation or not reported. One participant was excluded because she wanted to gain weight. The baseline characteristics of the two groups are described in Table 1.

\section{[TABLE 1]}

Some differences were found between participants completing all cost and body measurements and participants with at least one of these measurements missing, especially in the intervention group (Table 1). These variables were included in the imputation model. Imputed data concerned $20 \%$ of the cost variables, $20 \%$ of utilities, and $34 \%$ of the 18-month follow-up body measurements.

\section{Effectiveness}

Statistically significant differences in effects were found, in favor of the control group. Compared with the control group, the intervention group gained $1.6 \mathrm{~cm}$ in waist circumference and $1.1 \mathrm{~kg}$ in weight (Table 2). There were no differences in QALYs gained.

\section{[TABLE 2 ]}

\section{Resource Use and Costs}

Table 2 shows that presenteeism was statistically significantly higher by 52 hours in the intervention group. Mean intervention costs were $€ 218$, using OP labor costs, and $€ 497$, using OP charges. Total costs were similar, that is, €25,565 for the intervention group and $€ 25,664$ for the control group.

\section{Cost-Effectiveness}

The ICER for waist circumference was -62, indicating a societal saving of $€ 62 / \mathrm{cm}$ increase in waist circumference because of guideline care compared with usual care (Table 3). The ICER for body weight of -92 indicated a saving of $€ 92 / \mathrm{kg}$ increase in weight. The cost-effectiveness plane for waist circumference (Fig. 2A) shows substantial uncertainty. The cost-effectiveness acceptability curves show that the probability the guideline is cost-effective was around 52\% when the societal willingness to pay is zero for both outcomes. The probability decreased when willingness to pay increases (Fig. 2B).

\section{[FIGURE 2 ][TABLE 3]}


Wier, M.F. van, Verweij, L.M., Proper, K.I., Hulshof, C.T.J., Tulder, M.W. van, Mechelen, W. van. Economic evaluation of an occupational health care guideline for prevention of weight gain among employees. Journal of Occupational and Environmental Medicine: 2013, 55(9), 1101-1109

\section{Cost-Utility}

The incremental cost-utility ratio showed that €30,193 was saved per QALY lost because of the guideline in comparison with usual care (Table 3). The costeffectiveness plane (Fig. 2C) showed considerable uncertainty. The probability that the guideline is cost-effective for QALYs gained was $52 \%$ at a ceiling ratio of $€ 0$ and decreased with an increasing willingness to pay (Fig. 2D).

\section{Financial Return}

Table 4 shows a negative net employer benefit of $€-158$, but this was not statistically significant. For each Euro invested, $€ 0.68$ was retrieved, whereas the return on investment was $-32 \%$.

\section{[Table 4 ]}

\section{Sensitivity Analyses}

The sensitivity analyses revealed that the results found in the main analyses were not robust (Table 3). When analyses were restricted to complete cases (SA1), cost differences were in favor of the control group. The ICERs for weight loss and waist circumference represented losses in health at increased spending, whereas the incremental cost-utility ratio showed QALYs gained at increased costs. The probability of cost-effectiveness remained less than $40 \%$, regardless of willingness to pay (results not shown). The probability of cost-utility did not exceed $50 \%$. SA2, in which absenteeism and presenteeism were valued by using mean Dutch labor costs, resulted in higher costs in the intervention group. The probability of costeffectiveness reduced to less than $20 \%$ at any ceiling ratio for all outcomes (results not shown). The other sensitivity analyses showed probabilities of cost-effectiveness less than $62 \%$ for all outcomes (results not shown).

The sensitivity analyses for financial return are presented in Table 4. All showed financial losses, with the NB ranging from $€-15$ to $€-1910$. The latter NB, on the basis of the mean Dutch labor costs, was statistically significant.

\section{DISCUSSION}

An occupational health care guideline to prevent weight gain among employees had unfavorable effects on weight-related outcomes, no significant effect on QALYs gained, and a low probability of cost-effectiveness compared with usual care. From the perspective of a Dutch employer, the guideline resulted in a financial loss. Two other Dutch worksite interventions in which employees received 6 months of counseling on diet and physical activity had dissimilar outcomes. ${ }^{32,33}$ In the first one, overweight employees had access to either an interactive Web site or a written manual and were counseled by allied health care educators via e-mail or phone. Results of the economic evaluation conducted alongside this trial showed that 2 years after baseline, the internet condition resulted in (statistically not significant) weight loss and QALYs gained at low societal costs, whereas the NB for the employer was $€ 149$ (95\% CI, -858 to 618 ). ${ }^{32}$ In the second study, conducted among construction industry employees at increased risk for cardiovascular disease, face-to-face diet and physical activity counseling sessions were generally provided by occupational nurses. ${ }^{33}$ One year after baseline, an ICER of -145 (€293/-2.0 kg) was found, with a probability of cost-effectiveness of $60 \%$ at $€ 250 / \mathrm{kg}$ and $90 \%$ at $€ 2000 / \mathrm{kg}$. Nevertheless, employer's NB was negative, $€-254$ (95\% CI, -1536 to 1070). The 
Wier, M.F. van, Verweij, L.M., Proper, K.I., Hulshof, C.T.J., Tulder, M.W. van, Mechelen, W. van. Economic evaluation of an occupational health care guideline for prevention of weight gain among employees. Journal of Occupational and Environmental Medicine: 2013, 55(9), 1101-1109

differences between the studies may be explained by the health care professional that provided counseling. A review found that counseling by allied health care professionals and multidisciplinary teams produced better results than counseling by

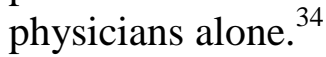

In the study by Groeneveld et $\mathrm{al}^{33}$ financial return seemed compromised by the charges of OPs and occupational nurses. The latter is confirmed in the current study, where benefits in terms of a reduction in absenteeism costs did not offset the intervention costs. This supports the use of cheaper health care professionals for counseling. Furthermore, results of this study support those of a recent systematic review in which it was concluded that workplace diet and physical activity interventions tested in RCTs show no immediate financial profit. ${ }^{31}$ In the case of effective interventions, this may be due to the short follow-up in most studies. If effects are sustained, interventions could prove to be profitable in the longer term. Effective interventions and more and longer RCTs are needed to verify this. The cost differences were sensitive to different valuations of productivity loss. When productivity loss was valued by using mean Dutch labor costs, the absenteeism cost difference decreased from $€-481$ to $€-147$, whereas the presenteeism cost difference increased from $€ 143$ to $€ 1561$ (see Table 4). This results from underlying interactions. The $€$-481 difference when labor cost was based on self-reported salary can be explained by lower absenteeism among higher-income employees in the intervention group, that is, an interaction between study group and income. Post hoc analyses (results not shown) confirm this. In addition, during follow-up, there was statistically significant more presenteeism in the intervention group. Post hoc analyses (results not shown) showed that in the main analysis, this difference was ruled out in the cost comparison because equivalent to absenteeism, presenteeism was lower (ie, the average work performance was better) among higher-income employees. In conclusion, only small reductions in absenteeism costs are likely in the guideline group, while increased presenteeism has an important and negative impact on the total cost differences when labor costs are equalized.

Workplace nutrition and physical activity programs of various designs, conducted in the Netherlands and in other countries, have largely shown small, short-term effects on body weight-, health-, and work-related measures. ${ }^{31,35,36}$ The results from this study are therefore in discord with the larger experience. Furthermore, the Netherlands occupational health care setting is exceptional in that nearly every Dutch worker has access to an OP and that nearly a quarter of these OPs are paid to provide preventive advice not directly related to work-related risks. Occupational physicians in other developed countries are not usually in that position. Despite lack of (cost)effectiveness and disparities in the organization of occupational health care, lessons can be learned from this study that could be of use in other jurisdictions. There may be several reasons why the program did not produce the desired results, pertaining to the design of the guideline and to its implementation. One of the rationales of the design was time restrictions, indicated by the OPs. Therefore a maximum of five counseling sessions was planned. This made the guideline wellstructured but probably not intensive enough. Reviews of worksite physical activity and nutrition programs suggest that more intensive and comprehensive interventions may be necessary to improve physical activity and dietary behavior.37-41 Weight gain prevention at the worksite could, for example, include more frequent counseling sessions, exercise schemes, and group counseling sessions. 
Wier, M.F. van, Verweij, L.M., Proper, K.I., Hulshof, C.T.J., Tulder, M.W. van, Mechelen, W. van. Economic evaluation of an occupational health care guideline for prevention of weight gain among employees. Journal of Occupational and Environmental Medicine: 2013, 55(9), 1101-1109

Also, in a process evaluation of the guideline, we found that intervention employees with higher attendance and satisfaction rates significantly improved their waist circumference and body weight. ${ }^{5}$ This suggests that the most motivated employees will reach better results. This is not surprising, because those who consider the sessions useful are more inclined to adhere to it and thus more likely to be able to control their weight. Thus, focusing on ways to motivate employees may pay off in effects. $^{42}$

A third point regarding the design of the guideline is that a previous study among Dutch OPs and occupational nurses showed that more elaborate counseling than we provided can be effective for inducing weight loss. ${ }^{43}$ Weight gain prevention programs should include behavioral-change counseling with sufficient time and attention for relapse prevention, changing OPs' routines, and support from colleagues, for example, through peer audit groups.

Last, pricing strategies, legislation, and changes in the physical and social environment have been proposed as promising strategies. ${ }^{44}$ Nevertheless, these interventions were not included in our study, and more research is needed to establish the effectiveness of these strategies in the work setting. With regard to the implementation of the guideline, the process evaluation showed that the guideline was not fully put into action. The motivational interviewing technique was provided well but not to its full extent. ${ }^{5}$ Because OPs claimed to have limited time, only 2 days of training were planned, but more training could be necessary to be fully proficient in the counseling techniques needed, especially if more complicated counseling techniques would be included in the guideline. Because this may not be feasible for OPs, it could be considered to have behavior-change counseling professionals such as health care educators and dietitians provide individual counseling. Another option would be to enlist other occupational health care providers such as occupational nurses for individual counseling. At the same cost, they could put more hours toward training and provide more counseling. Furthermore, only one intervention OP was able to realize changes in the company environment. The other OPs stated it was difficult to address the company environment because there were already (sufficient) events or facilities present, there was not enough time to implement changes, or that these changes did not get priority from the employer. In hindsight, the guideline could have provided OPs with better practical guidance and also with materials to implement simple environmental changes that have been shown to be effective, such as prompts, point-of-purchase signs, and food labeling. ${ }^{45,46}$ In addition, establishing a linkage board at each company could encourage support from both employers and employees. The OP training could be adapted to include OP-employer communication skills to better persuade employers to make environmental changes.

Finally, none of the OPs continued using the guideline after the 6-month intervention period, or the companies they serve did not adopt any of the guideline activities. Occupational physicians stated that continued use of the guideline was too difficult for them because the subject of weight gain prevention was neither linked to their work in occupational safety and disease management nor easy to embed within the company's policy. Even though overweight and obesity are acknowledged as major health threats and appear prominently on the Netherlands' public health agenda, Dutch companies do not seem ready to integrate prevention of overweight into their policies. 
Wier, M.F. van, Verweij, L.M., Proper, K.I., Hulshof, C.T.J., Tulder, M.W. van, Mechelen, W. van. Economic evaluation of an occupational health care guideline for prevention of weight gain among employees. Journal of Occupational and Environmental Medicine: 2013, 55(9), 110e-1109

The issues as discussed earlier make clear that although the guideline contains best evidence and practice recommendations, these recommendations did not sufficiently enhance employee health. Literature provides suggestions for improvements that may enhance the effectiveness of an adapted version of the guideline, such as a more intensive intervention, aimed at multiple individual and environmental factors, that provides better practical guidance and materials for OPs and is implemented well. Adapting the guideline, however, would not ensure that desired effects are produced. Moreover, these adaptations could lead to a guideline that may exceed what is feasible for OPs in routine practice. ${ }^{47}$ Considering the extent of the propositions, we suggest more research is needed on assessing strategies to achieve sustained effectiveness of workplace weight gain prevention.

\section{LIMITATIONS AND STRENGTHS OF THIS STUDY}

A limitation is the amount of missing data. Despite meticulous pursuit, data were missing for up to $34 \%$ of the measurements, a common problem with lifestyle intervention research conducted at the worksite. ${ }^{41}$ Furthermore, the self-report of all resource use may have led to an underestimation of the costs. In particular, absenteeism and presenteeism may have suffered from recall bias because the period on which to report was relatively long. ${ }^{14}$

A strength is the use of multiple imputation techniques, a recommended method to handle missing data. ${ }^{24,26}$ Furthermore, we conducted an economic evaluation alongside a RCT, which is the most valid design to evaluate effectiveness and allows for prospective cost-data collection.

\section{CONCLUSIONS}

Compared with usual care, care according to an occupational health care guideline to prevent weight gain among employees had a low probability of societal costeffectiveness and cost-utility. From the viewpoint of a Dutch employer, using the guideline resulted in a financial loss. Implementation of the guideline in its current form is not advised.

\section{ACKNOWLEDGMENTS}

We thank all OPs and employees who participated in this study.

\section{REFERENCES}

1. James WP. WHO recognition of the global obesity epidemic. Int J Obes (Lond). 2008;32(suppl 7):S120-S126.

2. Withrow D, Alter DA. The economic burden of obesity worldwide: a systematic review of the direct costs of obesity. Obes Rev. 2011;12:131-141.

3. Trogdon JG, Finkelstein EA, Hylands T, Dellea PS, Kamal-Bahl SJ. Indirect costs of obesity: a review of the current literature. Obes Rev. 2008;9:489-500.

4. Verweij LM, Proper KI, Weel AN, Hulshof CTJ, van Mechelen W. Design of the Balance@Work project: systematic development, evaluation and implementation of an occupational health guideline aimed at the prevention of weight gain among employees. BMC Public Health. 2009;9:461.

5. Verweij LM, Proper KI, Hulshof CT, van Mechelen W. Process evaluation of an occupational health guideline aimed at preventing weight gain among employees. J Occup Environ Med. 2011;53:722-729. Ovid Full Text

6. Verweij LM, Proper KI, Weel AN, Hulshof CT, van Mechelen W. The application of an occupational health guideline reduces sedentary behaviour and increases fruit intake at work: results from an RCT. Occup Environ Med. 2012;69:500-507. 
Wier, M.F. van, Verweij, L.M., Proper, K.I., Hulshof, C.T.J., Tulder, M.W. van, Mechelen, W. van. Economic evaluation of an occupational health care guideline for prevention of weight gain among employees. Journal of Occupational and Environmental Medicine: 2013, 55(9), 1101-1109

7. Verbeek J, Pulliainen M, Kankaanpaa E. A systematic review of occupational safety and health business cases. Scand J Work Environ Health. 2009;35:403-412.

8. Tompa E, Dolinschi R, de Oliveira C. Practice and potential of economic evaluation of workplace-based interventions for occupational health and safety. J Occup Rehabil. 2006;16:375-400.

9. EuroQol Group. EuroQol-a new facility for the measurement of health-related quality of life. Health Policy. 1990;16:199-208.

10. Lamers LM, Stalmeier PF, McDonnell J, Krabbe PF, van Busschbach JJ. Measuring the quality of life in economic evaluations: the Dutch EQ-5D tariff. Ned Tijdschr Geneeskd. 2005;149:1574-1578.

11. Hakkaart-van Roijen L, Tan SS, Bouwmans CAM. Manual for Cost Analysis. Methods and Standard Costs for Economic Evaluations in Health Care. Diemen, The Netherlands: Health Care Insurance Board; 2010.

12. Koopmanschap MA. PRODISQ: a modular questionnaire on productivity and disease for economic evaluation studies. Expert Rev Pharmacoecon Outcomes Res. 2005;5:23-28.

13. Koopmanschap MA, Rutten FFH, van Ineveld BM, van Roijen L. The friction cost method for measuring indirect costs of disease. J Health Econ. 1995;14:171-189.

14. Mattke S, Balakrishnan A, Bergamo G, Newberry SJ. A review of methods to measure health-related productivity loss. Am J Manag Care. 2007;13:211-217.

15. Kessler RC, Barber C, Beck A, Berglund P, Cleary PD, McKenas D. The World Health Organization Health and Work Performance Questionnaire (HPQ). J Occup Environ Med. 2003;45:156-174. Ovid Full Text

16. Kessler RC, Petukhova M, McInnes K, Üstün T B. Content and scoring rules for the WHO HPQ absenteeism and presenteeism questions. Available at: www.hcp.med.harvard.edu/hpq/info.php. Accessed October 26, 2011.

17. Kessler RC, Ames M, Hymel PA, Loeppke R, McKenas DK, Richling DE. Using the World Health Organization Health and Work Performance Questionnaire (HPQ) to evaluate the indirect workplace costs of illness. J Occup Environ Med. 2004;46:S23-S37. Ovid Full Text

18. Statistics Netherlands. Search by theme-Prices-Consumer prices-Consumer prices; price index 2006=100. http://statline.cbs.nl/StatWeb/publication/?DM=SLEN\&PA=71311ENG\&D1=0\&D2=0\&D3=6 4,77,90,103,116,129,142,155,168,181\&LA=EN\&WW=T. Accessed October 26, 2011.

19. Tan SS, Rutten FF, van Ineveld BM, Redekop WK, Hakkaart-van Roijen L. Comparing methodologies for the cost estimation of hospital services. Eur J Health Econ. 2009;10:3945.

20. de Zwart BCH, Prins R, van der Gulden JWJ. Report on the Position of the Occupational Physician. Leiden, the Netherlands: AStri Beleidsonderzoek en -advies; 2011.

21. Hooftman W, Klein Hesselink J, van Genabeek J, Wiezer N, Willems D. Arbobalance 2010. Quality of Labor, Effects and Measures in the Netherlands. Hoofddorp, the Netherlands: TNO; 2011.

22. Statistics Netherlands. Zoeken op thema-Bedrijvendemografie-Bedrijven-Bedrijven; grootte en rechtsvorm. Available at http://statline.cbs.nl/StatWeb/publication/?DM=SLNL\&PA=81588NED\&D1=114\&D2=0,3,9,13,52,54,59,63,70,77,80,90,94,98,108,117,119,121,127,132,136,139\&D3=2 \&VW=T. Accessed October 26, 2011.

23. van Buuren S, Boshuizen HC, Knook DL. Multiple imputation of missing blood pressure covariates in survival analysis. Stat Med. 1999;18:681-694.

24. Rubin DB. Multiple Imputation for Nonresponse in Surveys. New York, NY: John Wiley \& Sons; 1987.

25. Twisk J, Proper K. Evaluation of the results of a randomized controlled trial: how to define changes between baseline and follow-up. J Clin Epidemiol. 2004;57:223-228.

26. Burton A, Billingham LJ, Bryan S. Cost-effectiveness in clinical trials: using multiple imputation to deal with incomplete cost data. Clin Trials. 2007;4:154-161.

27. Black WC. The CE plane: a graphic representation of cost-effectiveness. Med Decis Making. 1990;10:212-214. 
Wier, M.F. van, Verweij, L.M., Proper, K.I., Hulshof, C.T.J., Tulder, M.W. van, Mechelen, W. van. Economic evaluation of an occupational health care guideline for prevention of weight gain among employees. Journal of Occupational and Environmental Medicine: 2013, 55(9), 110e-1109

28. Stinnett AA, Mullahy J. Net health benefits: a new framework for the analysis of uncertainty in cost-effectiveness analysis. Med Decis Making. 1998;18:S68-S80.

29. Phillips JJ. Return on Investment in Training and Performance Improvement Programs. Burlington, MA: Elsevier; 2003.

30. Stone PW. Return-on-investment models. Appl Nurs Res. 2005;18:186-189.

31. van Dongen JM, Proper KI, van Wier MF, et al. Systematic review on the financial return of worksite health promotion programmes aimed at improving nutrition and/or increasing physical activity. Obes Rev. 2011;12:1031-1049.

32. van Wier MF, Dekkers JC, Bosmans JE, et al. Economic evaluation of a weight control program with e-mail and telephone counseling among overweight employees: a randomized controlled trial. Int J Behav Nutr Phys Act. 2012;9:112.

33. Groeneveld IF, van Wier MF, Proper KI, Bosmans JE, van Mechelen W, van der Beek AJ. Cost-effectiveness and cost-benefit of a lifestyle intervention for workers in the construction industry at risk for cardiovascular disease. J Occup Environ Med. 2011;53:610-617.

34. Tulloch $\mathrm{H}$, Fortier $\mathrm{M}$, Hogg W. Physical activity counseling in primary care: who has and who should be counseling? Patient Educ Couns. 2006;64:6-20.

35. Robroek SJ, Polinder S, Bredt FJ, Burdorf A. Cost-effectiveness of a long-term Internetdelivered worksite health promotion programme on physical activity and nutrition: a cluster randomized controlled trial. Health Educ Res. 2012;27:399-410.

36. Bacon L, Aphramor L. Weight science: evaluating the evidence for a paradigm shift. Nutr J. 2011;10:9.

37. Ni MC, Aston LM, Jebb SA. Effects of worksite health promotion interventions on employee diets: a systematic review. BMC Public Health. 2010;10:62.

38. Conn VS, Hafdahl AR, Cooper PS, Brown LM, Lusk SL. Meta-analysis of workplace physical activity interventions. Am J Prev Med. 2009;37:330-339.

39. Dugdill L, Brettle A, Hulme C, McCluskey S, Long AF. Workplace physical activity interventions: a systematic review. Int J Workplace Health Manage. 2008;1:20-40.

40. Verweij LM, Coffeng J, van Mechelen W, Proper KI. Meta-analyses of workplace physical activity and dietary behaviour interventions on weight outcomes. Obes Rev. 2011;12:406429.

41. Anderson LM, Quinn TA, Glanz K, et al. The effectiveness of worksite nutrition and physical activity interventions for controlling employee overweight and obesity: a systematic review. Am J Prev Med. 2009;37:340-357.

42. Chan RS, Woo J. Prevention of overweight and obesity: how effective is the current public health approach. Int J Environ Res Public Health. 2010;7:765-783.

43. Groeneveld IF, Proper KI, van der Beek AJ, Hildebrandt VH, van Mechelen W. Short and long term effects of a lifestyle intervention for construction workers at risk for cardiovascular disease: a randomized controlled trial. BMC Public Health. 2011;11:836.

44. van der Lucht F, Polder JJ. Towards Better Health. Bilthoven, the Netherlands: National Institute for Public Health and the Environment; 2012.

45. Kwak L, Kremers SP, van Baak MA, Brug J. A poster-based intervention to promote stair use in blue- and white-collar worksites. Prev Med. 2007;45:177-181.

46. Engbers LH, van Poppel MN, Chin APM, van MW. Worksite health promotion programs with environmental changes: a systematic review. Am J Prev Med. 2005;29:61-70.

47. Grol R, Wensing M. What drives change? Barriers to and incentives for achieving evidence-based practice. Med J Aust. 2004;180:S57-S60 
Wier, M.F. van, Verweij, L.M., Proper, K.I., Hulshof, C.T.J., Tulder, M.W. van, Mechelen, W. van. Economic evaluation of an occupational health care guideline for prevention of weight gain among employees. Journal of Occupational and Environmental Medicine: 2013, 55(9), 11011109

TABLES AND FIGURES

FIGURE 1. Participant flow. Outcomes given in italics were used in the imputation model but not in the analyses. M, anthropometric measurement at OP office; OP, occupational physician; Q, questionnaire; QALYs, quality-adjusted life-years; WC, waist circumference.

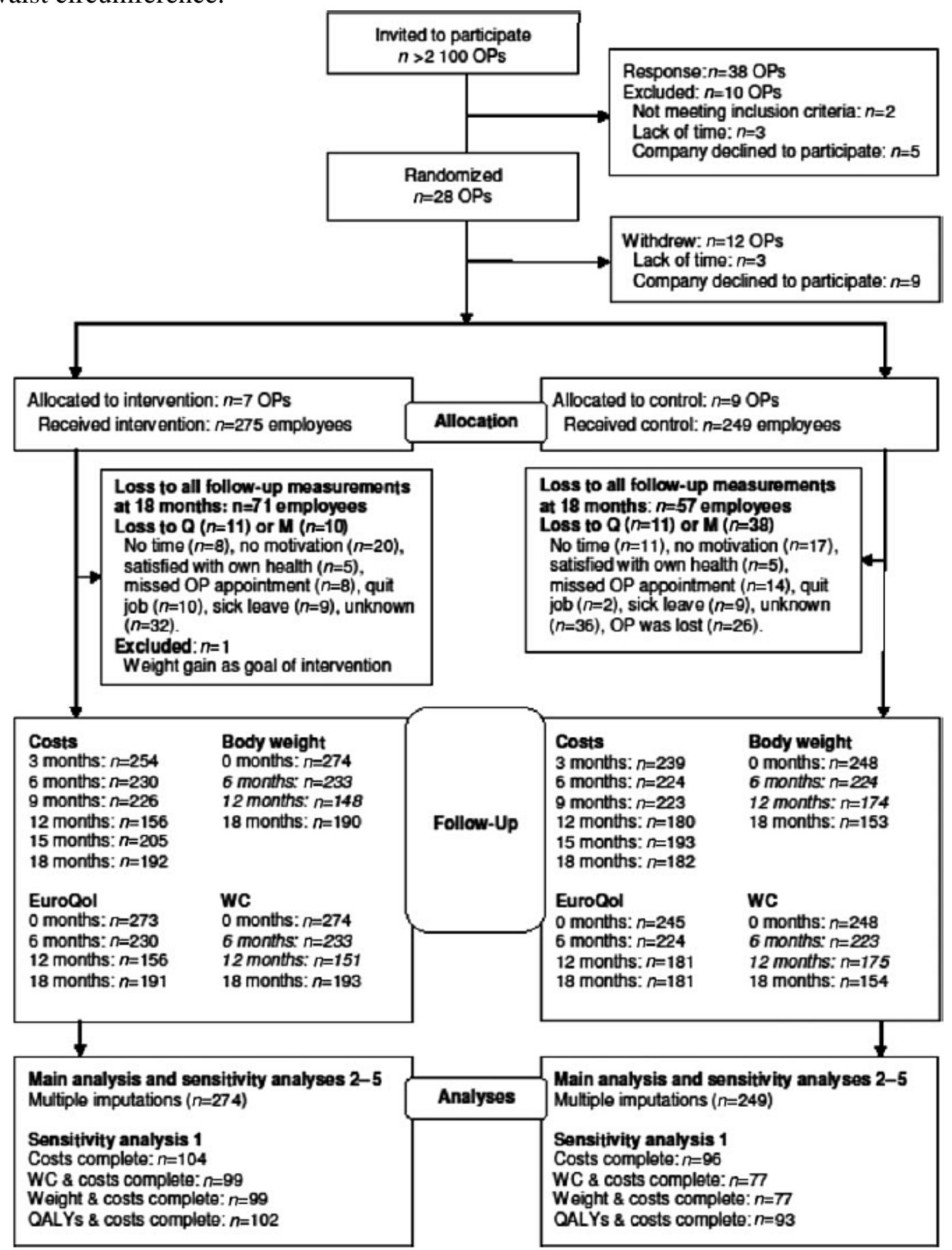




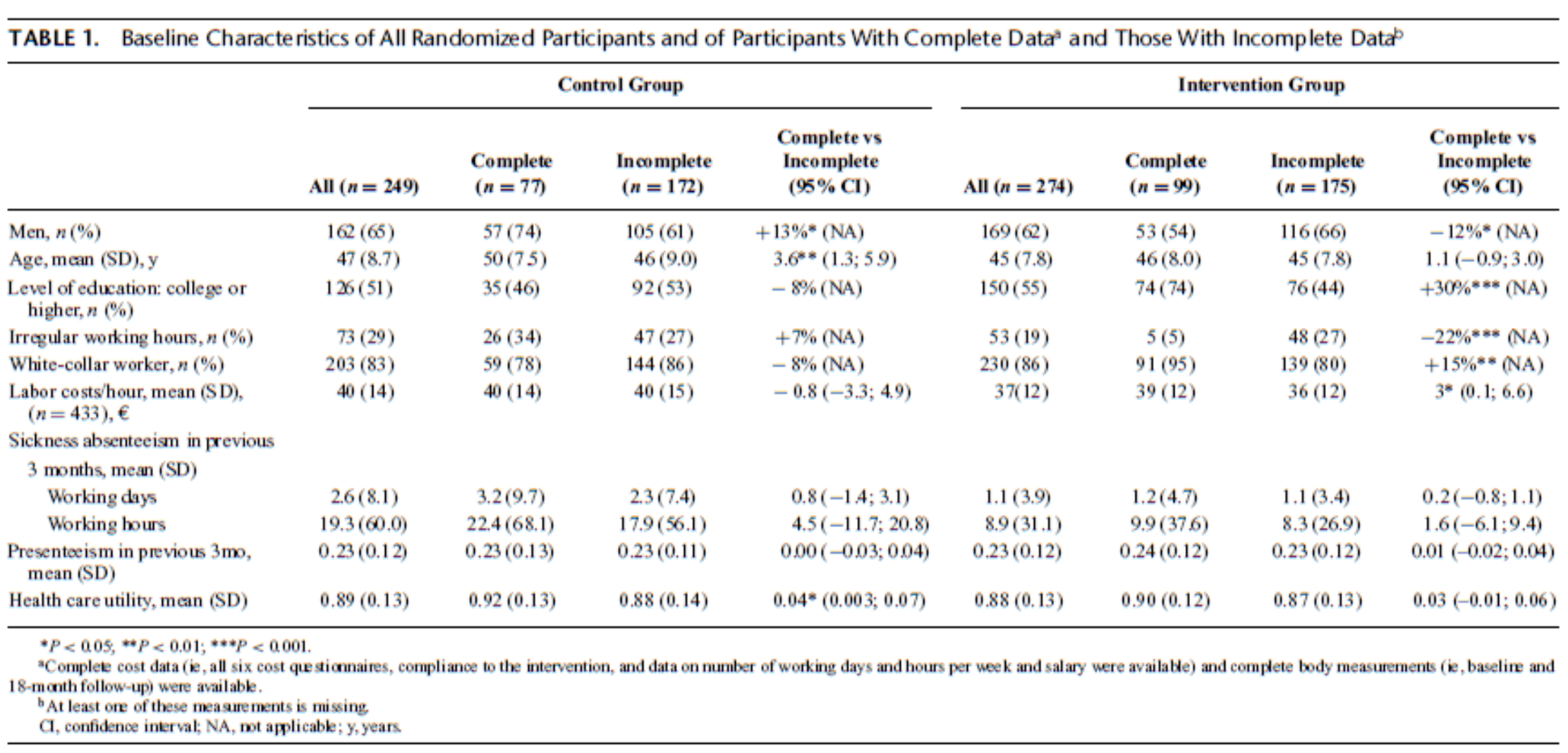




\begin{tabular}{|c|c|c|c|c|c|}
\hline & \multicolumn{2}{|c|}{ Intervention Group ( $n=249$ ) } & \multicolumn{2}{|c|}{ Control Group $(n=274)$} & \multirow{2}{*}{$\begin{array}{c}\text { Intervention vs Control, } \\
\text { Mean Difference } \\
(95 \% \mathrm{CI})\end{array}$} \\
\hline & $\begin{array}{l}\text { Baseline Mean } \\
\text { (SEM) }\end{array}$ & $\begin{array}{c}\text { Follow-Up Mean } \\
\text { (SEM) }\end{array}$ & $\begin{array}{l}\text { Baseline Mean } \\
\text { (SEM) }\end{array}$ & $\begin{array}{c}\text { Follow-Up Mean } \\
\text { (SEM) }\end{array}$ & \\
\hline \multicolumn{6}{|l|}{ Outcome } \\
\hline $\mathrm{WC}, \mathrm{cm}$ & $94.5(0.79)$ & $95.3(0.91)$ & $98.0(0.86)$ & $96.7(0.84)$ & $1.6^{*}(0.27 ; 2.90)$ \\
\hline Body weight, $\mathrm{kg}$ & $86.0(1.05)$ & $86.4(1.03)$ & $87.6(1.07)$ & $86.9(1.09)$ & $1.1 *(0.01 ; 2.15)$ \\
\hline QALY $^{\mathrm{b}}$ achieved & - & $1.37(0.011)$ & - & $1.38(0.009)$ & $-0.006(-0.029 ; 0.017)$ \\
\hline \multicolumn{6}{|l|}{ Resource use } \\
\hline Counseling sessions & - & $4.2(0.09)$ & - & - & - \\
\hline Sickness absenteeism, FCA, h & - & $89(14)$ & - & $94(13)$ & $-5(-41 ; 31)$ \\
\hline Presenteeism, h & - & $559(14)$ & - & $507(13)$ & $52 * * *(15 ; 89)$ \\
\hline \multicolumn{6}{|l|}{ Costs per category, $€$} \\
\hline Intervention & - & $218(4)$ & - & $0(0)$ & 218 (NA) \\
\hline Primary health care & - & $398(48)$ & - & $390(46)$ & $8(-122 ; 140)$ \\
\hline Secondary health care & - & $410(89)$ & - & $381(57)$ & $29(-161 ; 248)$ \\
\hline Participant & - & $564(44)$ & - & $580(48)$ & $-16(-144 ; 107)$ \\
\hline Absenteeism & - & $3,043(540)$ & - & $3,524(569)$ & $-481(-1,852 ; 972)$ \\
\hline Presenteeism & - & $20,932(723)$ & - & $20,789(914)$ & $143(-2,158 ; 2,416)$ \\
\hline Total costs, $€$ & - & $25,565(908)$ & - & $25,664(1,194)$ & $-99(-2,918 ; 2,772)$ \\
\hline
\end{tabular}

* $P<0.05 ; * * * P<0.01$

Costs are expressed in 2009 Euros.

The maximum amount of QALYs that can be achieved in 18 months is 1.5 units.

CI, confidence interval; FCA, friction cost approach; h, hours; NA, not applicable; QALY, quality-adjusted life-year; SEM, standard error of the mean; WC, waist circumference 
Wier, M.F. van, Verweij, L.M., Proper, K.I., Hulshof, C.T.J., Tulder, M.W. van, Mechelen, W. van. Economic evaluation of an occupational health care guideline for prevention of weight gain among employees. Journal of Occupational and Environmental Medicine: 2013, 55(9), 110^1109

nivel

TABLE 3. Incremental Cost-Effectiveness Ratios and Distribution of the Joint Cost-Effect Pairs in the Cost-Effectiveness Plane $^{a}$

\begin{tabular}{|c|c|c|c|c|c|c|c|c|c|}
\hline \multirow[b]{2}{*}{ Analysis ${ }^{\mathbf{b}}$} & \multicolumn{2}{|c|}{ Sample Size Per Group } & \multirow[b]{2}{*}{$\Delta \mathrm{C}(95 \% \mathrm{CI}), €$} & \multirow{2}{*}{ 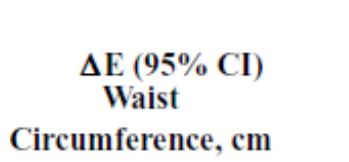 } & \multirow[b]{2}{*}{ ICER } & \multicolumn{4}{|c|}{$\begin{array}{l}\text { Distribution in CE } \\
\text { Plane (\%) }\end{array}$} \\
\hline & Control & Intervention & & & & $\mathrm{NE}^{\mathrm{c}}$ & $S E^{d}$ & swe & NWf \\
\hline $\begin{array}{l}\text { Main analysis: imputed } \\
\text { data sets }\end{array}$ & 249 & 274 & $-99(-2,918 ; 2,772)$ & $1.6^{*}(0.27 ; 2.90)$ & -62 & 0.4 & 0.5 & 52.0 & 47.1 \\
\hline SA1: complete cases & 77 & 99 & $651(-3,414 ; 4,097)$ & $0.4(-1.4 ; 2.1)$ & 1,705 & 20.8 & 12.2 & 21.6 & 45.4 \\
\hline $\begin{array}{l}\text { SA2: mean Dutch labor } \\
\text { costs }\end{array}$ & 249 & 274 & $1,653 *(35 ; 3,286)$ & $1.6^{*}(0.27 ; 2.90)$ & 1,041 & 0.7 & 0.0 & 2.2 & 97.0 \\
\hline SA3: HCA & 249 & 274 & $22(-3,117 ; 3,013)$ & $1.6^{*}(0.27 ; 2.90)$ & 14 & 0.3 & 0.4 & 48.6 & 50.6 \\
\hline \multirow{2}{*}{$\begin{array}{l}\text { SA4: excluding } \\
\text { presenteeism }\end{array}$} & 249 & 274 & $-242(-1,846 ; 1,385)$ & $1.6^{*}(0.27 ; 2.90)$ & -153 & 0.2 & 0.5 & 61.8 & 37.4 \\
\hline & Control & Intervention & $\Delta \mathrm{C}(95 \% \mathrm{CI}), €$ & Body Weight, kg & ICER & NE & SE & sw & NW \\
\hline $\begin{array}{l}\text { Main analysis: imputed } \\
\text { data sets }\end{array}$ & 249 & 274 & $-99(-2,918 ; 2,772)$ & $1.1^{*}(0.01 ; 2.15)$ & -92 & 0.7 & 1.1 & 51.1 & 47.1 \\
\hline SA1: complete cases & 77 & 99 & $651(-3,414 ; 4,097)$ & $0.7(-0.6 ; 1.9)$ & 964 & 7.1 & 6.4 & 29.3 & 57.1 \\
\hline $\begin{array}{l}\text { SA2: mean Dutch labor } \\
\text { costs }\end{array}$ & 249 & 274 & $1,653^{*}(35 ; 3,286)$ & $1.1 *(0.01 ; 2.15)$ & 1,529 & 1.7 & 0.1 & 2.2 & 96.0 \\
\hline SA3: HCA & 249 & 274 & $22(-3,117 ; 3,013)$ & $1.1^{*}(0.01 ; 2.15)$ & 20 & 0.7 & 1.0 & 47.7 & 50.6 \\
\hline \multirow{2}{*}{$\begin{array}{l}\text { SA4: excluding } \\
\text { presenteeism }\end{array}$} & 249 & 274 & $-242(-1,846 ; 1,385)$ & $1.1^{*}(0.01 ; 2.15)$ & -224 & 0.6 & 1.2 & 60.7 & 37.5 \\
\hline & Control & Intervention & $\Delta \mathrm{C}(95 \% \mathrm{CI}), €$ & QALY & ICUR & NE & SE & sw & NW \\
\hline $\begin{array}{l}\text { Main analysis: imputed } \\
\text { data sets }\end{array}$ & 249 & 274 & $-99(-2,918 ; 2,772)$ & $-0.006(-0.029 ; 0.017)$ & 16,118 & 12.4 & 16.3 & 35.9 & 35.4 \\
\hline SA1: complete cases & 93 & 102 & $707(-2,745 ; 4,144)$ & $0.006(-0.022 ; 0.035)$ & 117,872 & 41.1 & 25.4 & 9.6 & 23.9 \\
\hline $\begin{array}{l}\text { SA2: mean Dutch labor } \\
\text { costs }\end{array}$ & 249 & 274 & $1,653 *(35 ; 3,286)$ & $-0.006(-0.029 ; 0.017)$ & $-269,097$ & 28.3 & 1.4 & 0.9 & 69.4 \\
\hline SA3: HCA & 249 & 274 & $22(-3,117 ; 3,013)$ & $-0.006(-0.029 ; 0.017)$ & $-3,649$ & 13.6 & 15.9 & 32.8 & 37.7 \\
\hline $\begin{array}{l}\text { SA4: excluding } \\
\text { presenteeism }\end{array}$ & 249 & 274 & $-242(-1,846 ; 1,385)$ & $-0.006(-0.029 ; 0.017)$ & 39,441 & 5.9 & 23.3 & 39.1 & 31.7 \\
\hline
\end{tabular}

\footnotetext{
$* P<0.05$.

${ }^{\mathrm{a} C}$ Costs are expressed in 2009 Euros.

${ }^{\mathrm{b}}$ In the analysis, $\Delta \mathrm{C}=$ mean difference in total costs of intervention versus control, $\Delta \mathrm{E}=$ mean difference in outcome, ICER (ICUR) is calculated as $\Delta \mathrm{C} / \Delta \mathrm{E}$. In the intention-to-treat analysis, missing data were multiply imputed. The complete cases analysis was restricted to participants with complete cost and effect data.

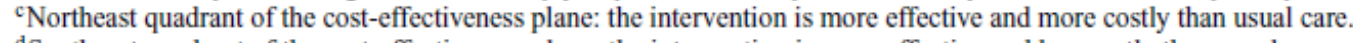

${ }^{\mathrm{d}}$ Southeast quadrant of the cost-effectiveness plane: the intervention is more effective and less costly than usual care.

eSouthwest quadrant of the cost-effectiveness plane: the intervention is less effective and less costly than usual care.

${ }^{\mathrm{f}}$ Northwest quadrant of the cost-effectiveness plane: the intervention is less effective and more costly than usual care.

CE, cost-effectiveness; CI, confidence interval; HCA, human capital approach; ICER, incremental cost-effectiveness ratio; ICUR, incremental cost-utility ratio; NE, northeast; NW, northwest; QALY, quality-adjusted life-year; SA, sensitivity analysis; SE, southeast; SW, southwest.
} 
Wier, M.F. van, Verweij, L.M., Proper, K.I., Hulshof, C.T.J., Tulder, M.W. van, Mechelen, W. van. Economic evaluation of an occupational health care guideline for prevention of weight gain among employees. Journal of Occupational and Environmental Medicine: 2013, 55(9), 110^1109

FIGURE 2. A, Cost-effectiveness plane for waist circumference of the guideline group compared with usual care group. B, Cost-effectiveness acceptability curve for waist circumference of the guideline group compared with usual care group. C, Costeffectiveness plane for QALYs gained in the guideline group compared with usual care group. D, Cost-effectiveness acceptability curve for QALYs gained in the guideline group compared with usual care group. QALYs, qualityadjusted life-years.

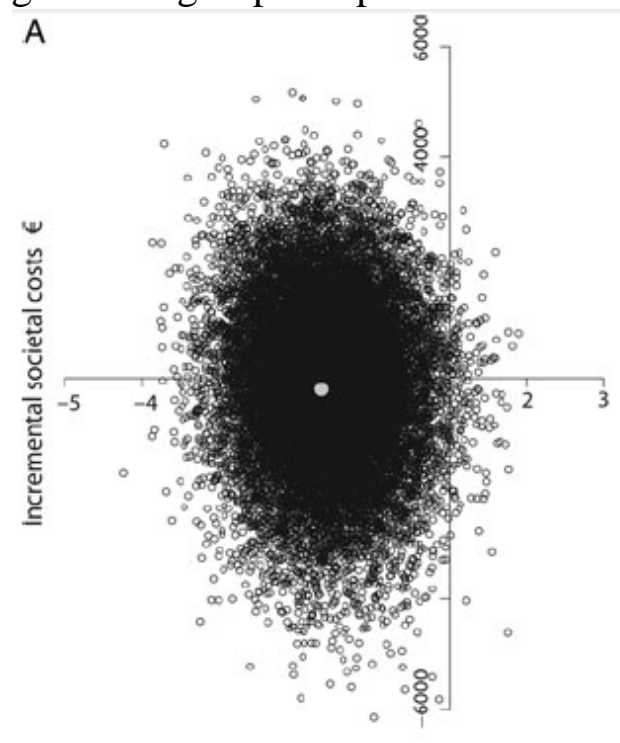

Incremental decrease in waist circumference. $\mathrm{cm}$

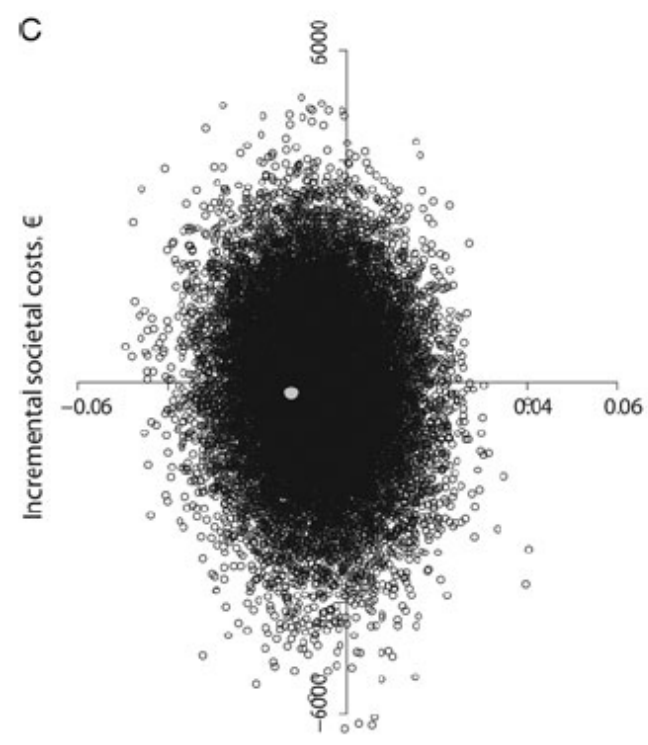

Incremental OALYs gained

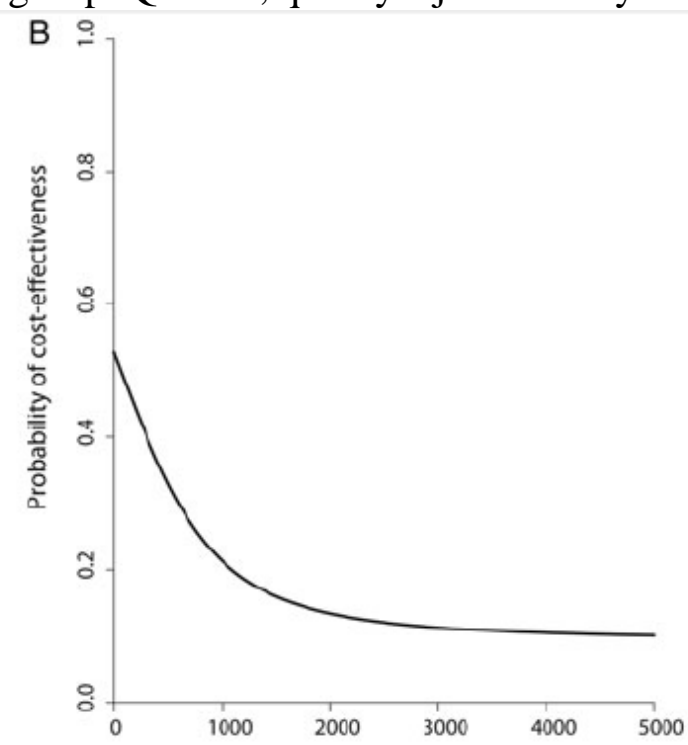

Willingness to pay per $1 \mathrm{~cm}$ decrease in waist circumference, $€$

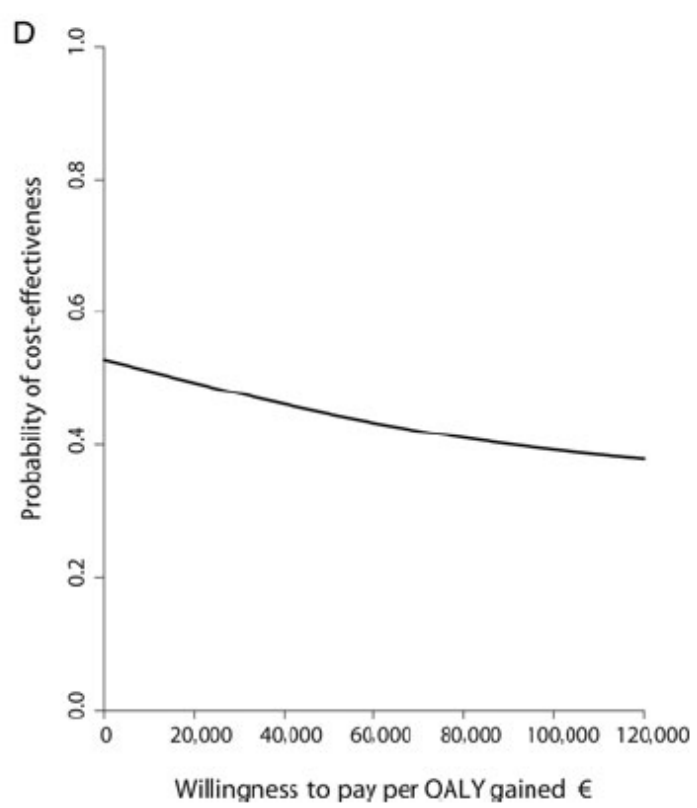

